Abdominal pain

\section{An unusual cause of abdominal pain}

\section{P Wilkinson, J M Norcross, A R Wood, J D Stevenson, $M$ Vassallo}

\section{Answers on $p 665$.}

A 54 year old man came to the emergency department with acute postprandial abdominal pain, vomiting, and collapse. He was known to have learning difficulties, chronic renal impairment, and hypertension. There were no other systemic symptoms. On examination he was apyrexial, he had a heart rate of 90 beats/min, a blood pressure of $80 / 50 \mathrm{~mm} \mathrm{Hg}$, and oxygen saturations of $97 \%$ on air. His chest was clear, there were no cardiac murmurs, and abdominal examination revealed a tender fullness over the right flank and hypochondrium. Lesions were noted over the second, third, and fifth toes of the left foot (fig 1).

His initial investigations showed a haemoglobin of $83 \mathrm{~g} / \mathrm{l}$, mean corpuscular volume $88.3 \mathrm{fl}$, international normalised ratio 0.95, activated partial thromboplastin time $57.9 \mathrm{sec}$ (control $32.2 \mathrm{sec}$ ) which partially corrected to $37.8 \mathrm{sec}$ with a 50/50 mix, sodium

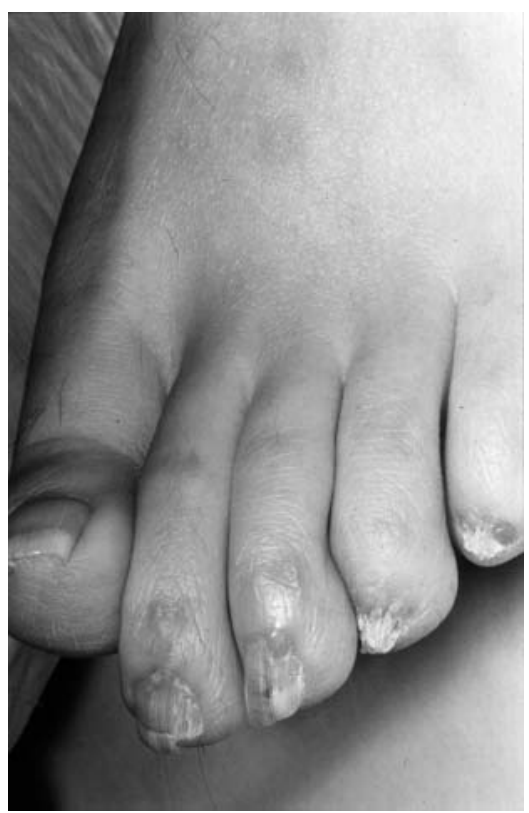

Figure 1 Patient's toes showing lesions.
$135 \mathrm{mmol} / \mathrm{l}$, potassium $4.6 \mathrm{mmol} / \mathrm{l}$, urea $28.7 \mathrm{mmol} / \mathrm{l}$, creatinine $475 \mu \mathrm{mol} / \mathrm{l}$, calcium $2.34 \mathrm{mmol} / \mathrm{l}, \quad$ magnesium $0.75 \mathrm{mmol} / \mathrm{l}$, phosphate $1.57 \mathrm{mmol} / \mathrm{l}$, amylase $67 \mathrm{IU} / \mathrm{l}$, albumin $36 \mathrm{~g} / \mathrm{l}$, liver function normal, and urine, blood, and stool culture sterile. Chest and abdominal plain radiographs were unremarkable. Over the next 24 hours the haemoglobin fell to $57 \mathrm{~g} / \mathrm{l}$ requiring transfusion. A gastroscopy showed grade 1 oesophagitis, a normal stomach, pylorus, and Dl. A prominent ampulla at D2 was noted, showing non-specific small bowel mucosa on biopsy. A further drop in haemoglobin occurred, associated with increased abdominal pain. Faecal occult blood was negative and no external rectal bleeding was noted. Direct Coombs test was negative, reticulocyte count $27 \times 10^{9} / 1(50-100 \times$ $10^{9} / 1$ ), and haptoglobins were $0.3 \mathrm{~g} / \mathrm{l}$

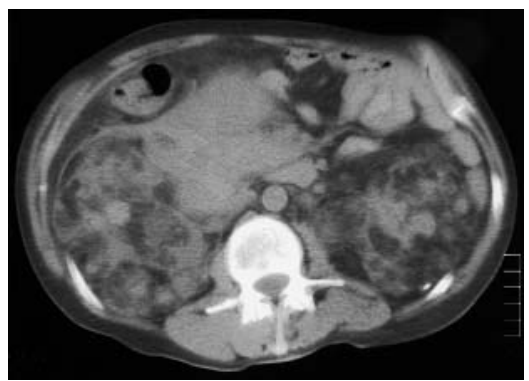

Figure 2 Computed tomogram.

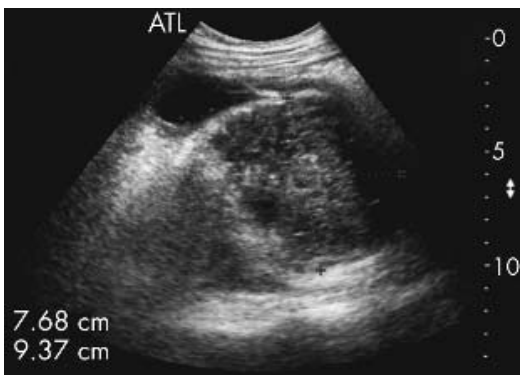

Figure 3 Initial ultrasound scan

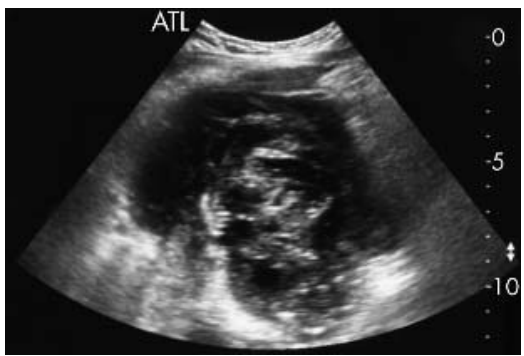

Figure 4 Ultrasound scan at two weeks.

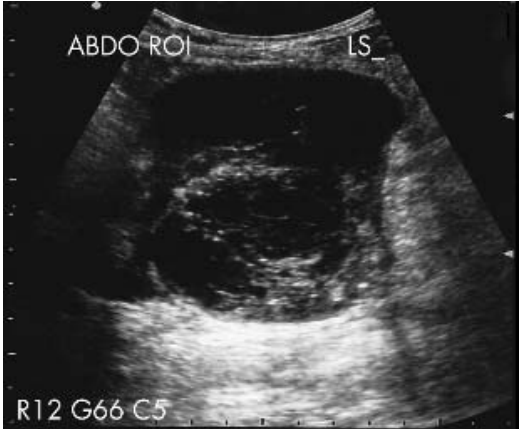

Figure 5 Ultrasound scan at six weeks.

(0.5-2.4). Repeat abdominal examination revealed a large mass in the right hypochondrium.

He had an abdominal computed tomography (fig 2). This was followed up over a six week period with serial ultrasound scans (figs 3, 4, and 5).

\section{QUESTIONS}

(1) What is the diagnosis and what are the clinical features of this condition?

(2) What does the computed tomogram of the abdomen (fig 2) show?

(3) What do the renal ultrasound scans (figs $3,4,5$ ) show and what is the likely diagnosis?

(4) What is the cause of the clotting abnormality?

Postgrad Med J 2003;79:661

\section{Authors' affiliations}

C P Wilkinson, J M Norcross, A R Wood, J D Stevenson, M Vassallo, Department of Medicine, Royal Bournemouth and Christchurch Hospitals NHS Trust, Bournemouth, Dorset

Correspondence to: Dr Michael Vassallo, Royal Bournemouth and Christchurch Hospitals NHS Trust, Castle Lane East, Bournemouth BH7 7DW, UK; michael.vassallo@ rbch-tr.swest.nhs.uk

Submitted 13 November 2002

Accepted 5 December 2003 